\title{
Visualization of DNA-protein intermediates during activation of the Pu promoter of the TOL plasmid of Pseudomonas putida
}

\author{
Junkal Garmendia and Víctor de Lorenzo
}

Centro Nacional de Biotecnología CSIC, Campus de Cantoblanco, 28049 Madrid, Spain
Author for correspondence: Víctor de Lorenzo. Tel: +34 91585 4536. Fax: +34 915854506. e-mail:vdlorenzo@cnb.uam.es

The ATP-dependent multimerization process undergone by the $\sigma^{54}$-dependent activator XYIR of the TOL plasmid pWWO of Pseudomonas putida when bound to the upstream activating sequences (UAS) of the cognate Pu promoter was examined by transmission electron microscopy (TEM). To this end, supercoiled DNA templates were combined with increasing concentrations of the constitutive XyIR variant XyIRAA, with or without ATP or its non-hydrolysable analogue ATP $\gamma$ S, and the resulting complexes were visualized by TEM. The different types of DNA-protein association were analysed and a statistical study of the frequency of the various forms was made. ATP appeared to establish an equilibrium between different molecular associations, as well as major changes in the physical shape of the DNA-protein complexes. The formation of higher nucleoprotein structures frequently bearing DNA bends became manifest. Such complexes often engaged otherwise separated UAScontaining plasmids, indicating that the ATP-driven multimer included XyIR molecules recruited in trans. Whilst ATP caused the different types of XyIR-DNA complex to occur at quite balanced frequencies, ATP $\gamma$ appeared to displace the distribution predominantly towards the higher order forms. These data are compatible with the notion that each time ATP is hydrolysed the transcriptional activation complex is disassembled.

Keywords: Pseudomonas putida, TOL plasmid, Pu promoter, sigma 54, enhancers

\section{INTRODUCTION}

Pseudomonas putida strains carrying the TOL plasmid $\mathrm{pWW} 0$ can grow in toluene as the only carbon source due to the activity of two catabolic operons (Assinder \& Williams, 1990). Expression of the upper operon is driven by the $\sigma^{54}$-dependent promoter $P u$ which, like other promoters of this type, is activated at a distance by the enhancer-binding and toluene-responsive protein XylR (Abril et al., 1991; Pérez-Martín \& de Lorenzo, 1996b). This process also requires the integration host factor (Abril et al., 1991; de Lorenzo et al., 1991), a binding sequence for which is present within the intervening region between the upstream activating sequences (UAS) bound to XylR and the $-12 /-24$ sequence motifs for $\sigma^{54}$-RNA polymerase holoenzyme (Fig. 1a). XylR belongs to the group of activators that

Abbreviations: TEM, transmission electron microscopy; UAS, upstream activating sequences. act in concert with $\sigma^{54}$ and are generically known as the NtrC family, named after the most studied member of the group (North et al., 1993). All these proteins seem to share a common mechanism of activation of their cognate promoters when bound to the UAS. Also like these proteins, XylR has a three-domain structure (Drummond et al., 1986; Inouye et al., 1988). The Nterminal or A domain is a signal receptor module that interacts directly with the aromatic effector, for example substrates of the TOL upper pathway (Delgado \& Ramos, 1994). This event releases the intramolecular repression that the A domain exerts in the protein, thus generating an active form of the regulator. As a consequence, protein variants deleted of the A domain are constituive and can activate transcription in vivo (Pérez-Martín \& de Lorenzo, 1995) and in vitro (PérezMartín \& de Lorenzo, 1996c) in the absence of the aromatic inducer. The A domain is connected to the central C module through a supposedly flexible linker or $\mathrm{B}$ domain. The central $\mathrm{C}$ domain is the most conserved region of this type of protein; it provides the ATPase 
(a)

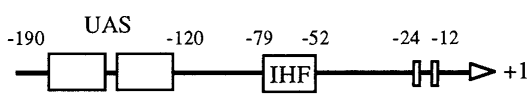

(b)

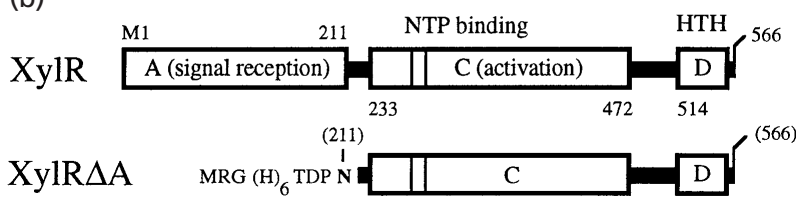

(c)

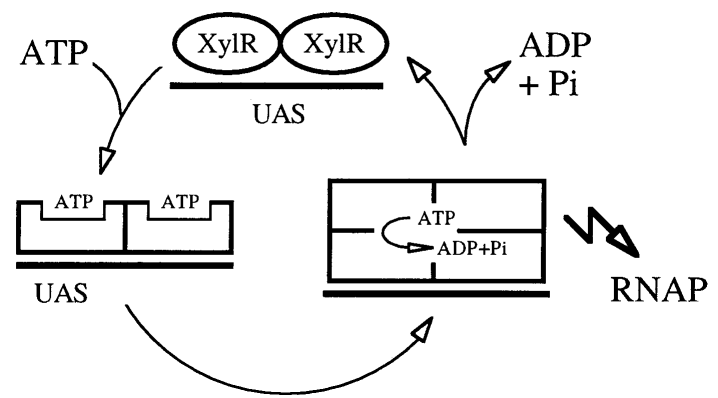

Fig. 1. Organization and functioning of the XylR-responsive promoter Pu. (a) Structure of the $\sigma^{54}$-dependent $P u$ promoter. The distribution of relevant DNA sequences inserted in test plasmid pEZ9 (de Lorenzo et al., 1991) is shown. These include the UAS for XyIR and the $-12 /-24$ region recognized by $\sigma^{54}$ RNA polymerase (RNAP). The promoter also contains a functional integration host factor (IHF)-binding site located within the intervening region. (b) Functional domains of XylR and its truncated and constitutive derivative $\mathrm{XyIR} \Delta \mathrm{A}$. Relevant portions of the protein sequence include the signal reception, $\mathrm{N}$-terminal A domain, the central $\mathrm{C}$ module involved in NTP binding, and the $\mathrm{D}$ domain at the C-terminus, with a helix-turn-helix $(\mathrm{HTH})$ motif for DNA binding. The leading residues of the XyIR $\triangle A$ protein, deleted entirely of the $A$ domain, but with a $\mathrm{His}_{6}$ coil added at the $\mathrm{N}$ terminus, is also indicated. (c) Simplified model (Pérez-Martín \& de Lorenzo, 1996a) for the multimerization cycle of XyIR at the UAS of the $\mathrm{Pu}$ promoter. Following the release of intramolecular repression caused by $m$-xylene binding to the A domain of XylR, the protein bound to its cognate sequences at the $P u$ enhancer undergoes a conformational change upon ATP binding that makes the protein competent to form a multimer. This may involve just a spatial rearrangment of adjacent proteins already bound to DNA or, alternatively, recruitment of additional XyIR from solution. The multimer is then able to hydrolyse ATP and channel the released energy into transcription initiation by the polymerase. The complex may then return to a nonmultimerized state.

activity that is required for transcriptional activation and presumably interacts with the $\sigma^{54}$ factor for the eventual formation of a transcriptionally competent open complex. Finally, the C-terminal domain of XylR contains a helix-turn-helix motif for binding the UAS of the $P u$ promoter (Inouye et al., 1988; Morett \& Segovia, 1993).

Fig. 1(c) summarizes the series of events that, according to the model proposed by Pérez-Martín \& de Lorenzo (1996a), follow the release of the intramolecular re- pression caused by $m$-xylene binding to the A domain of XylR. Within this scheme, the activator bound to its cognate sequences at the $P u$ promoter cyclically changes its conformation upon ATP binding to build up a protein multimer that is competent to hydrolyse ATP and to channel the released energy into transcription initiation by the polymerase. This model is favoured by data (Pérez-Martín \& de Lorenzo, 1996a) from DNase I footprinting, from monitoring of the conformational states brought about by ATP binding to XylR, and from the behaviour of XylR variants apparently locked in either a non-multimerized state $(\mathrm{G} 268 \mathrm{~N})$ or a multimerized state $(\mathrm{R} 453 \mathrm{H})$. The weakness of this model was the very circumstantial evidence for the proposition that the multimer becomes disassembled every time ATP is hydrolysed. This was largely based on the observation that mutant R453H (Fig. 1) seemed to keep the complex in a multimerized state but yet was unable to activate transcription. The behaviour of this mutant is, however, somewhat ambiguous. Whilst it footprinted the DNA and auto-crosslinked with a pattern similar to that of the wild-type protein in the presence of ATP (Pérez-Martín $\&$ de Lorenzo, 1996a), an equivalent mutation found in $\mathrm{NtrC}(\mathrm{R} 358 \mathrm{H})$ lacked any ATP-binding ability (North $e t$ al., 1996) and there was doubt over whether it polymerized spontaneously (Li et al., 1999). These observations encouraged us to re-examine the issue of the ATP-driven multimerization cycle proposed for XylR with a different technique, namely direct visualization of protein-DNA complexes by transmission electron microscopy (TEM). The work presented here analyses the effect of the ATP in the formation of different types of oligomeric complexes and their distribution under various conditions. The results are consistent with the reported transitions in the DNA-protein contacts observed by DNase I footprinting assays brought about by ATP (Pérez-Martín \& de Lorenzo, 1996a). Moreover, the data are compatible with the notion of an ATP-driven cycle as the basis for the transcriptional activation of $P u$.

\section{METHODS}

Plasmids and general techniques. Plasmid pEZ9 (2987 bp), which bears the entire sequence of $P u$ inserted as a $301 \mathrm{bp}$ EcoRI-BamHI fragment $(-208$ to +93 of the promoter region) has been described previously (de Lorenzo et al., 1991). Its parental vector, pUC18, was used as the insertless control in the TEM experiments reported below. Metallo-affinity purification of the His-tagged $\mathrm{XylR} \Delta \mathrm{A}$ protein was described in detail by Pérez-Martín \& de Lorenzo (1996b). High-purity plasmid DNA for TEM experiments was prepared by ultracentrifugation in isopycnic gradients of $\mathrm{CsCl}$ (Maniatis et al., 1982).

Preparation of samples for TEM of XylRAA-DNA complexes. Specimens for examination with the electron microscope were prepared by mixing the DNA under examination at a final concentration of $1 \mathrm{ng}$ DNA $\mu^{-1}$ with increasing amounts of purified $\mathrm{XylR} \Delta \mathrm{A}$ ranging from $5 \mathrm{nM}$ to $300 \mathrm{nM}$ in an assay buffer containing $20 \mathrm{mM}$ Tris/ $\mathrm{HCl} \mathrm{pH} 7 \cdot 5,2 \mathrm{mM} \mathrm{MgCl}_{2}$, $1 \mathrm{mM}$ EDTA and $40 \mathrm{mM} \mathrm{KCl}$. Where indicated, $5 \mathrm{mM}$ ATP or its non-hydrolysable structural analogue $\mathrm{ATP} \gamma \mathrm{S}$ was added 
to the mixtures. The final volume of each reaction was $50 \mu \mathrm{l}$. The components were premixed on ice and incubated for $20 \mathrm{~min}$ at $30^{\circ} \mathrm{C}$. Reactions were then stopped by cooling, the mixtures were diluted twofold in the same buffer and $0 \cdot 1 \%$ glutaraldehyde was added for fixation, followed by incubation for $30 \mathrm{~min}$ at $37^{\circ} \mathrm{C}$. The reaction was then stopped by adding $\mathrm{NH}_{4} \mathrm{Cl}$ to a final concentration of $10 \mathrm{mM}$. Fifty microlitres of each sample was layed on a piece of Parafilm for $15 \mathrm{~min}$ to let complexes become located homogeneously at the drop surface. The drops were then adsorbed to the inner face of an exfoliated mica piece for $20 \mathrm{~s}$ and dried. The samples underwent three $90 \mathrm{~min}$ washes with sterile water, followed by an additional washing step with absolute ethanol to dehydrate them. The alcohol was then removed to total dryness and the samples were rotary-shadowed with a platinum and carbon spray at a $3^{\circ}$ angle using BALZERS $400 \mathrm{~T}$ cryofracture equipment. The layers resulting from the shadowing were floated away from the mica and recovered on copper grids that were inspected in an electron microscope (JEOL JEM-1200 EXII). TEM images were captured at a magnification of $\times 30000$.

Image analysis and statistical breakdown. An average of 100-150 random plasmid molecules in the TEM images were inspected in each condition to produce enough samples for a statistically significant analysis. The fidelity of the statistical breakdown was monitored by examination of the error rate in the confidence interval corresponding to $P=0.95$ (error rate $0-4.9 \%$ ) and $P=0.99$ (error rate $0-6.3 \%$ ).

\section{RESULTS AND DISCUSSION}

\section{Rationale for the TEM analysis: ATP increases the occupation by XyIR $\Delta \mathrm{A}$ of nonspecific DNA sequences adjacent to the UAS of $P u$}

It has been reported previously (Pérez-Martín \& de Lorenzo, 1996b) that XylR binding in vitro to the two sites present at the $\mathrm{Pu}$ enhancer (termed, respectively, distal and proximal) is not cooperative per se, i.e. full occupation of the proximal site occurs at much lower protein concentrations than the distal one. However, ATP addition causes a marked cooperativity in the binding of XylR $\Delta \mathrm{A}$ to the two sites of the $P u$ enhancer. This has been reported to alter the pattern of DNAprotein interactions between the activator and the target UAS as detected by DNase I footprinting. A close inspection of the footprinting data of Pérez-Martín \& de Lorenzo (1996a) reveals an interesting feature of the DNA-XylR $\Delta$ A contacts. Addition of ATP caused $\mathrm{XylR} \Delta \mathrm{A}$ not only to fully bind the two UAS, but also to significantly protect the region immediately upstream of the distal UAS. It should be noted that in these and in all other experiments presented below, we used an XylR variant that has been deleted of its $\mathrm{N}$ terminus (XylR $\Delta \mathrm{A}$; Fig. 1) and is thus frozen in the constitutively active form equivalent to the protein after activation by $m$-xylene (Pérez-Martín \& de Lorenzo, 1996c). The extension of the DNase I protection, which engaged at least 44 additional bp upstream of the UAS, is not easy to explain. The enlargement of the footprint occurs towards the $5^{\prime}$ end of the promoter sequence, and thus cannot simply be attributed to a nonspecific polymerization of the protein along the DNA by an excess of protein. A possible explanation could be that a protein multimer brought about by ATP binding could be wrapped by the DNA nucleated around the primary binding sites (the UAS). Since this is anticipated to cause a major change in the physical form of the DNA, we resorted to TEM of the protein-DNA complexes to examine the issue directly, and also to visualize possible intermediates of the XylR oligomerization cycle proposed for the activation of the $P u$ promoter (PérezMartín \& de Lorenzo, 1996a).

\section{Typology of simple XyIRAA-DNA complexes visualized by TEM}

To gain an insight into the structural changes undergone by the XylR-DNA complexes during activation of $P u$, we prepared mixtures of pEZ9, a supercoiled plasmid bearing the $P u$ promoter as a $301 \mathrm{bp}$ fragment (Fig. 1a), and the purified protein XylR $\Delta \mathrm{A}$. As mentioned above, $\mathrm{XylR} \Delta \mathrm{A}$ resembles the form of the protein that follows the release of intramolecular repression upon exposure to TOL inducers (Férnandez et al., 1995; Pérez-Martín $\&$ de Lorenzo, 1996c). The complexes may thus reflect the type of DNA-protein associations that exist after that step in vivo. The mixtures of $\mathrm{pEZ} 9$ and XylR $\Delta \mathrm{A}$ were made at concentrations that are significant in ATPase (Pérez-Martín \& de Lorenzo, 1996c), footprinting (Pérez-Martín \& de Lorenzo, 1996b) and in vitro transcription assays (Pérez-Martín \& de Lorenzo, 1996c) and in a buffer whose composition was similar to that used for these assays. In all $(100 \%)$ cases, the TEM images obtained from preparations of pEZ9 devoid of any protein corresponded to the form that in Fig. 2 is termed type I (single, naked plasmid contours devoid of any attached electron-dense spots). On this basis, we examined samples with increasing concentrations of $\mathrm{XylR} \Delta \mathrm{A}$ without any other addition (Fig. 3). Even at protein concentrations as low as $10 \mathrm{nM}$, we started to detect a proportion of the species named type IIA in Fig. 2. These bear visible electron-dense, well-defined dots attached to the plasmid contour and are likely to reflect the simpler XylR $\Delta \mathrm{A}-\mathrm{UAS}$ complexes detected with DNase I (Pérez-Martín \& de Lorenzo, 1996a). Both type I and type IIA forms remained well discernible at higher protein concentrations (Fig. 3), although the bulk of the plasmids in the samples remained in the unbound form. At $100 \mathrm{nM}$ protein, another species (named type III in Fig. 2), although minor $(<15 \%)$, became apparent as well. This form consisted of associations of two plasmids nucleated around a bigger electron-dense dot. Further increases in $\mathrm{XylR} \Delta \mathrm{A}$ concentrations (up to $300 \mathrm{nM}$ ) resulted in large aggregates, which were considered artefactual and thus were disregarded for further studies (not shown). When the same experiments were made with plasmid pUC18 devoid of the $P u$ insert, every image observed corresponded to the type I form (not shown). This suggested that the electron-dense spots observed upon simple addition of $\mathrm{XylR} \Delta \mathrm{A}$ to pEZ9 corresponded to genuine $\mathrm{XylR} \Delta \mathrm{A}-\mathrm{P} u$ complexes. Since the type I form (naked plasmids) was predominant $(60-100 \%)$ at both the protein concentrations used, we concluded that in the absence of any other addition, the 


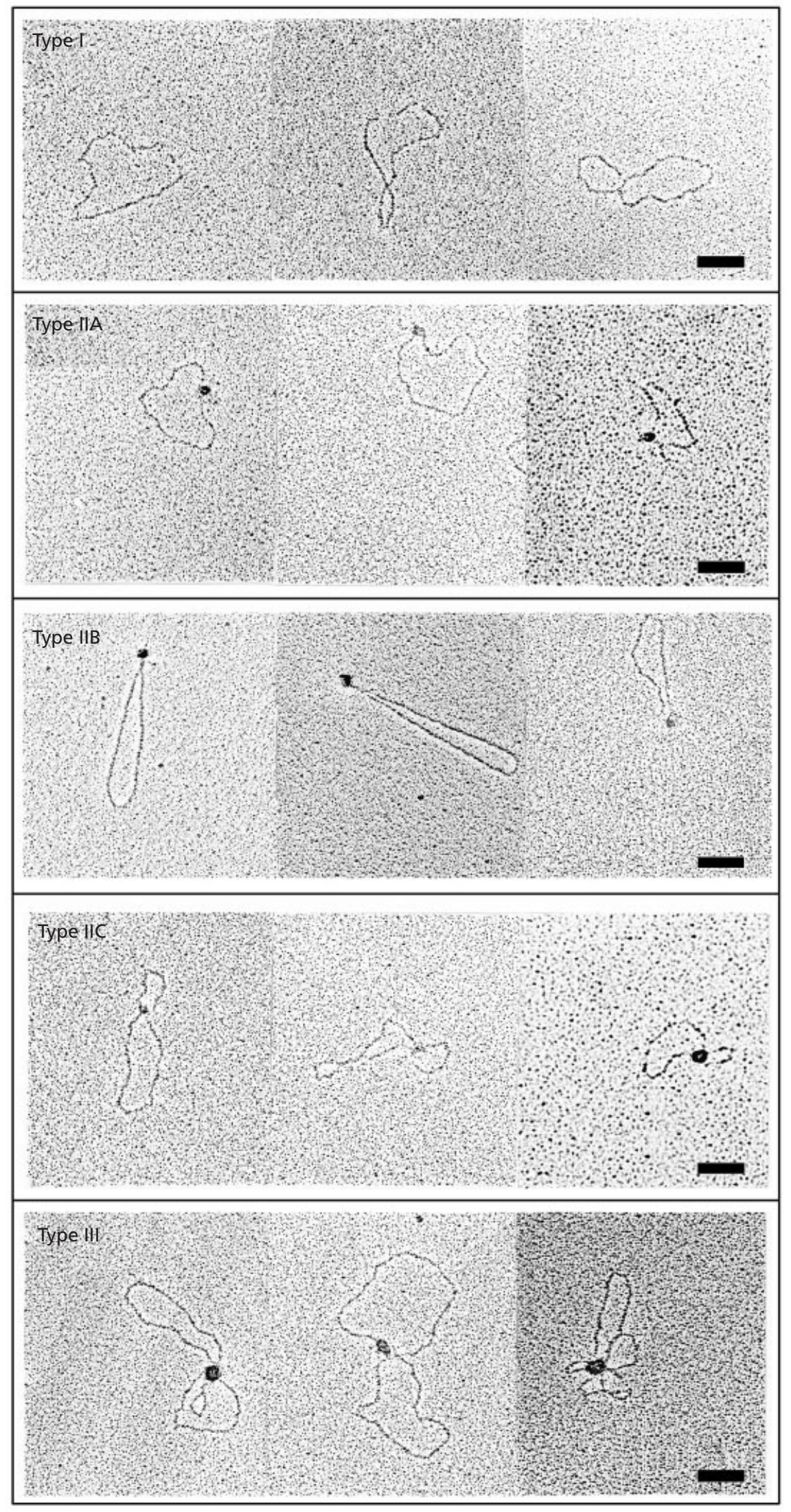

Fig. 2. For legend see facing page. 


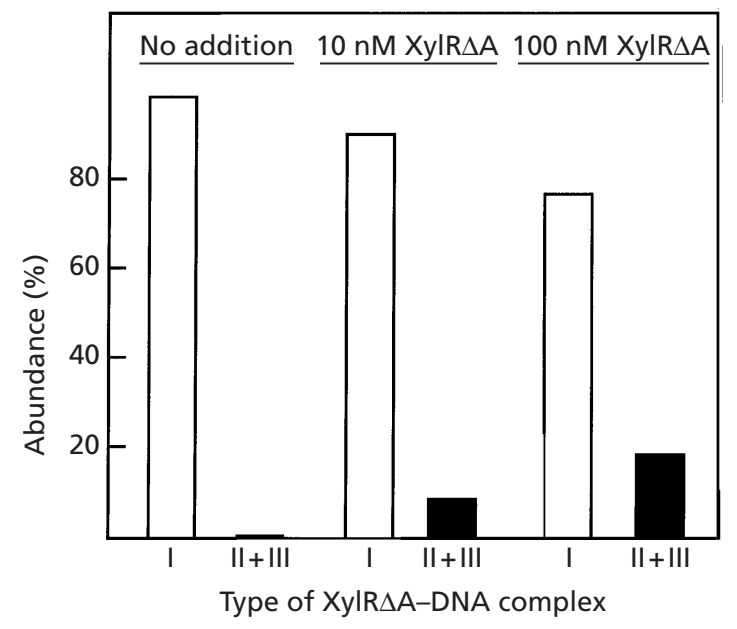

Fig. 3. Spontaneous formation of DNA complexes between $P u$ containing plasmids and XyIR $\Delta \mathrm{A}$ in the absence of ATP. The bar diagrams show the results of counting bound and unbound DNA-protein complexes as visualized by TEM. Plasmid pEZ9 was prepared at a concentration of $900 \mathrm{ng} \mathrm{ml}^{-1}$ and mixed with the indicated amounts of purified XyIR $\triangle A$ without ATP. Following a short incubation, samples were fixed with glutaraldehyde, adsorbed to a mica surface, shadowed and deposited on a grid for inspection by TEM as described in Methods. The most abundant associated form was type IIA (Fig. 2). The type III form never exceeded about $5 \%$ of the total image counts. The population size examined was 100-150 molecules and the results have an error rate of $0-6 \%$ as measured within a confidence interval corresponding to $P=0.99$. Note that a $10-$ fold augmentation in protein concentration produces only a small increase in the percentage of DNA-protein complexes.

interaction of $\mathrm{XylR} \Delta \mathrm{A}$ with $P u$ is transient and that $\mathrm{XylR} \Delta \mathrm{A}$ does not have per se an important affinity for the UAS. This matches previous results with DNase I footprint assays (Pérez-Martín \& de Lorenzo, 1996a) in which full occupation of the proximal site of the UAS (Fig. 1) was only detected at XylR $\Delta \mathrm{A}$ concentrations of $100 \mathrm{nM}$, whilst the occupation of the distal site required concentrations of the activator higher than $800 \mathrm{nM}$.

\section{Effect of ATP on the distribution of XyIRAA-DNA complexes}

ATP binding and hydrolysis are the key events for the conversion of XylR $\Delta \mathrm{A}$ in a transcriptionally competent regulator. To examine how the nucleotide affected the formation and appearance of DNA-protein complexes, we prepared samples for TEM in the same fashion as above, but adding to the mixtures $5 \mathrm{mM}$ ATP. The

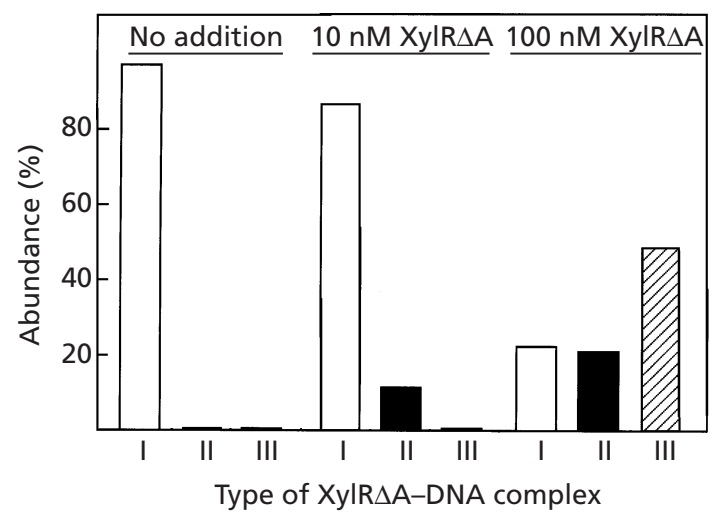

Fig. 4. Effect of ATP on the formation and morphology of XylR $\triangle A$ A-DNA complexes. The bar diagrams show the results of counting the different species of DNA-protein complexes visualized by TEM under various incubation conditions. Plasmid pEZ9 was prepared at a concentration of $900 \mathrm{ng} \mathrm{ml}^{-1}$ and mixed with the indicated amounts of purified XylR $\triangle A$ with $5 \mathrm{mM}$ ATP. The abundance of complexes of types I, II and III is indicated. The population size examined was in all cases 100-150 molecules and the results have an error rate of $0-6 \%$ within a confidence interval corresponding to $P=0.99$. Note the very significant effect of ATP addition at $100 \mathrm{nM}$ XyIR $\Delta$ A. Complexes of type IIB were observed exclusively in samples with ATP added, where they accounted for approximately onequarter of the complexes examined. Complexes of type IIC were rare $(<5 \%)$, but were also confined to ATP-treated samples.

resulting images were more diverse than their counterparts without ATP (Fig. 4). Besides the type I and type IIA forms already seen, we also observed the interesting shape that we refer to as type IIB. Similar to type IIA, this new structure shows a plasmid contour bearing one electron-dense dot, but in this case it acts as the apex of a sharply bent DNA segment. Another novel structure became visible when the samples were added with ATP, named type IIC (Fig. 2). In this case, one electron-dense dot indistinguishable from those seen in types IIA and IIB appeared to contact simultaneously otherwise separated DNA sequences within the same plasmid. The three type II forms involving single plasmids with single dots in different arrangements coexisted in all samples with $\mathrm{XylR} \Delta \mathrm{A}$ and $\mathrm{ATP}$. In no case was a significant reduction in the size of the plasmid contour detected. However, the sum of all type II forms was still a relatively minor proportion of the total images at the lower concentrations of the protein (10 nM; Fig. 4). At the higher concentration (100 $\mathrm{nM} \mathrm{XylR \Delta A})$, however, the frequency of these forms equalled that of the naked plasmids. In addition, multi-plasmid complexes became

Fig. 2. Typology of XylR-DNA complexes with isolated plasmids bearing the $P u$ promoter sequence. The photographs show representative images of the different types of DNA-protein (XyIR $\Delta A$ ) complexes found with individual Pu-bearing plasmids pEZ9 as detected by TEM. The electron-dense dots are presumably DNA-protein complexes. The type I form consists of naked plasmid contours. Type II are plasmid contours bearing single, well-defined, electron-dense dots. This type includes three morphologies: IIA, in which the dot is attached to plasmids without any apparent structural restriction; IIB, bearing one electron-dense dot, which acts as the apex of a sharply bent DNA segment; and IIC, in which one electron-dense dot appears to contact simultaneously otherwise separated DNA sequences within the same plasmid. Finally, type III are multi-plasmid XyIR $\triangle$ A-DNA complexes, consisting of the association of two or more plasmids nucleated around a electron-dense dot larger than those observed in the complexes with isolated plasmids of type II. Bars, $100 \mathrm{~nm}$. 
the most abundant form in samples with $100 \mathrm{nM}$ of the protein (Fig. 4). Similar to the situation mentioned above for the samples without ATP, control plasmid pUC18 produced no forms other than type I even at the higher protein concentrations assayed. This again suggested that the changes in appearance and distribution of the complexes upon ATP addition reflected significant variations undergone by the system upon ATP addition.

Inspection of the $\mathrm{XylR} \Delta \mathrm{A}-\mathrm{DNA}$ associations in the presence of ATP, as compared to those in its absence (see above) revealed two informative features. First, that the type IIB form (single plasmids sharply bent at an apex with an electron-dense dot) appeared exclusively in the presence of ATP. Second, that intra- and intermolecular plasmid associations (types IIC and III), became predominant only at the higher concentrations of the protein and in the presence of ATP (Fig. 4). In other words, it appeared that ATP addition caused $\mathrm{XylR} \Delta \mathrm{A}$ to adopt a form which bears non-saturated DNA-binding sites and is thus able to interact with otherwise distant DNA sequences in the same plasmid (type IIC) or even in trans with a different plasmid (type III). Furthermore, the frequency of type IIC and III forms (Fig. 4) in the samples with $100 \mathrm{nM} \mathrm{XylR \Delta A}$ plus ATP as compared to the same samples without the nucleotide (Fig. 3) suggested that ATP causes the protein to oligomerize into a form able to bind two DNA sequences separated in cis or in trans. Whilst in the case of the inter-molecular associations (type III), the protein oligomer probably engages plasmids specifically anchored through the UAS, it is possible that in the type IIC complexes (intra-molecular associations), the lack of specificity is compensated by the physical proximity of the bound DNA.

Another interesting aspect of the distribution of XylR $\Delta \mathrm{A}-\mathrm{DNA}$ forms in the samples with $100 \mathrm{nM}$ protein and ATP (Fig. 4) is the coexistence of all visual forms (types I, II and III) at quite balanced frequencies. This is not the case in the absence of ATP, where the predominant forms are the naked plasmids and the simple associations. We believe that this diversity of forms reflects the population of different protein-DNA species that arise during the hydrolysis of ATP so that the frozen images represent distinct stages of the process. In fact, that higher complexes subsist along with naked plasmid molecules suggests a cycle of XylR binding, oligomerization into a form able to bind distant DNA molecules, and then dissassembly of the complex.

\section{ATP $\gamma S$ fixes the XyIR $\triangle A-D N A$ complexes in the higher order forms}

Since ATP hydrolysis is a dynamic process, the hypothesis of a protein-DNA oligomerization cycle driven by the nucleotide makes some predictions that can be examined by TEM. In particular, that the addition of a non-hydrolysable ATP analogue (such as ATP $\gamma$ S) to the $\mathrm{XylR} \triangle \mathrm{A}-\mathrm{DNA}$ samples should eliminate the diversity of forms and displace all molecular species towards the

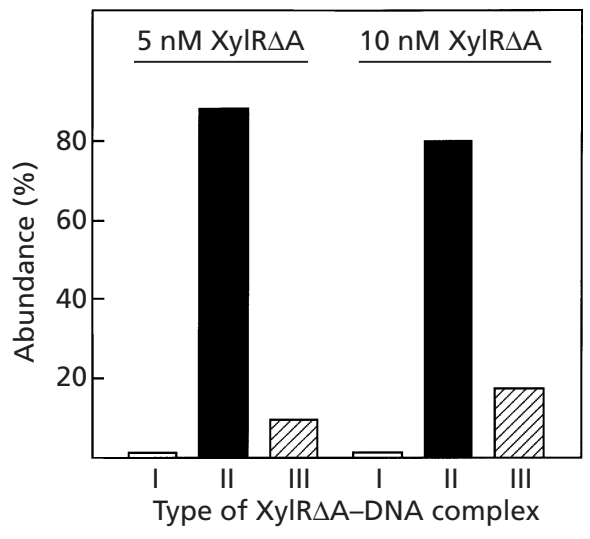

Fig. 5. Effect of $A T P \gamma S$ addition in the interaction of $X y I R \triangle A$ with $P u$. The bar diagrams show the results of counting the DNA-protein complexes made in the presence of $5 \mathrm{mM} \mathrm{ATP} \gamma \mathrm{S}$ at low $\mathrm{XyIR} \triangle \mathrm{A}$ concentrations and visualized with TEM. The population size examined was in both cases 100-150 molecules and the results have an error rate of $0-5 \%$ within a confidence interval correspondng to $P=0.99$. Note that naked plasmids disappeared from the visual field $(\geqslant 1 \%)$ and single-plasmid protein-DNA complexes became the predominant form. The forms involving sharply bent DNA (type IIB; Fig. 2) were not observed in any of the samples treated with the nonhydrolysable ATP analogue.

complex formed just following ATP binding but prior to ATP hydrolysis. This is facilitated by the observation (Pérez-Martín \& de Lorenzo, 1996a) that the affinity of $\mathrm{ATP} \gamma \mathrm{S}$ for $\mathrm{XylR} \Delta \mathrm{A}$ is comparable to that of its nonhydrolysable counterpart. To ensure the visualization of events occurring on individual plasmids (rather than involving two or more), we ran the corresponding experiments with $\mathrm{ATP} \gamma \mathrm{S}$ using a low range of concentrations of $\mathrm{XylR} \Delta \mathrm{A}(5$ and $10 \mathrm{nM})$ within which some effects started to be detected with ATP (Fig. 4). The analysis of the resulting images (Fig. 5) clearly revealed that the predominant forms $(\geqslant 90 \%)$ of the molecules even at the lowest protein concentration were those in which individual plasmids were bound by one single electron-dense dot (type IIA). Only at higher protein concentrations did multi-plasmid associations start to increase in frequency, becoming fully dominant at $\geqslant 20 \mathrm{nM}$ (not shown). Interestingly, the type I form (naked plasmids) entirely disappeared from the visual field $(\leqslant 1 \%)$ at any protein concentration in the range $5-50 \mathrm{nM}$ in the presence of ATP $\gamma$, thereby suggesting that every available DNA target was engaged in stable interactions with the protein. Taken together, these results suggested that ATP binding (but not its hydrolysis) both increases the affinity of XylR $\Delta$ A for DNA and gives rise to the protein species able to bind simultaneously two or more distant DNA sequences. Finally, the loss of diversity of complexes at the lower protein concentrations in the presence of ATP $\gamma \mathrm{S}$ (Fig. 5) as compared to the distribution of forms with ATP (Fig. 4) is consistent with the notion that ATP hydrolysis drives a protein multimerization/disassembly cycle that is interrupted at the early multimer stage if the nucleo- 


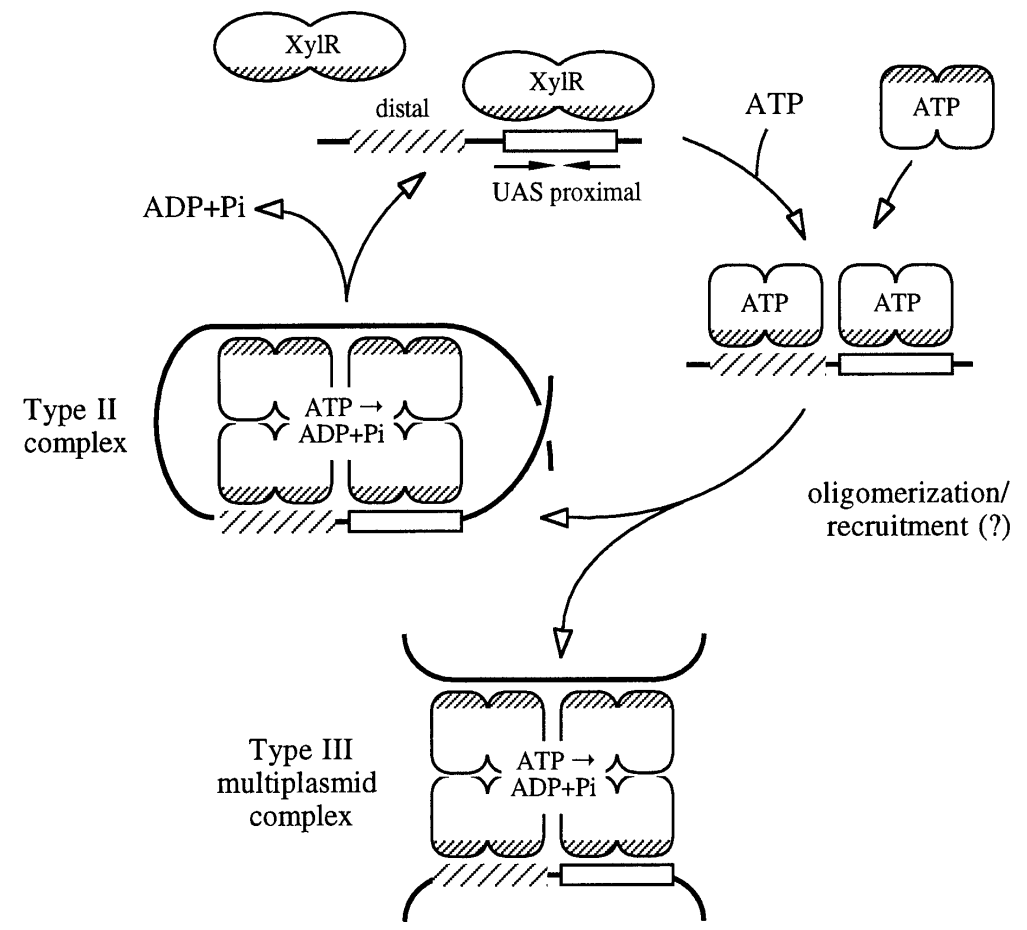

Fig. 6. Model for the ATP-driven
multimerization cycle of XyIR. The events
undergone by XylR $\Delta A$ upon exposure to
ATP in vivo or in vitro are represented as an
oligomerization cycle. In the absence of ATP,
XyIR $\Delta A$ dimers have little affinity for the
UAS (the proximal site is the primary
binding site). ATP causes a conformational
change in the protein that both increases
the affinity and cooperativity of the
protein-DNA interaction and provokes the
buildup of a larger oligomer (perhaps an
octamer, as represented) with more XylR $\Delta A$
proteins from solution. The resulting
complex, which displays spatially separated
and non-saturated DNA-binding domains,
may interact either with adjacent sequences,
thus becoming the core of a crossed loop
(visualized in the type IIB form), or with
other UAS in trans (type III), forming a
multiplasmid complex. ATP hydrolysis
disassembles the protein multimer, thus
driving the system back to the non-
multimerized form. The formation of a
crossed loop of adjacent sequences may
explain the sharp DNA bend observed in
complexes of type IIB.

tide is not hydrolysed (see below). Inspection of the various complexes formed in the presence of $\mathrm{ATP} \gamma \mathrm{S}$ also revealed the virtual absence of type IIB forms, in which the DNA seems to be sharply bent in association with the protein. This suggested that production of such species may be dependent on ATP hydrolysis.

\section{Conclusion: oligomerization of XylR during activation of $\mathrm{Pu}$}

The TEM images presented in this work need to be interpreted in the light of what has already been reported on the interactions of $\mathrm{XylR} \Delta \mathrm{A}$ with the UAS of $P u$ by using DNase I (Pérez-Martín \& de Lorenzo, 1996a) and hydroxyl radical footprinting (Pérez-Martín \& de Lorenzo, 1996b), and on the various studies on the archetype of $\sigma^{54}$-dependent enhancer-binding proteins, NtrC (Rippe et al., 1998). Although our former work was done with linear DNA and the work presented here largely involves supercoiled DNA, we did not find any incompatibility in the outcome of the respective experiments. From the early DNase I footprint analyses (PérezMartín \& de Lorenzo, 1996b), it was clear that in the absence of ATP, the binding of $\mathrm{XylR} \Delta \mathrm{A}$ was somewhat weak and non-cooperative. This has its TEM counterpart in the abundance of naked plasmids in samples treated with $\mathrm{XylR} \Delta \mathrm{A}$ concentrations of $10-100 \mathrm{nM}$ in the absence of the nucleotide (Fig. 3). ATP changes the protein-DNA interaction pattern (Pérez-Martín \& de Lorenzo, 1996a) in two ways. On one hand, it increases dramatically the affinity and the cooperativity of the protein for the UAS, but on the other hand, it extends the protection from DNase I towards the $5^{\prime}$ region of the promoter. These changes could correspond to the transition between type II forms A and B (Fig. 2), in which the protein bound to the DNA appears to nucleate a sharp DNA bend. A simple explanation for this (Révet et al., 1995) could be that XylR $\Delta \mathrm{A}$ dimers bound to adjacent UAS may interact with each other upon ATP addition and thus bend the intervening DNA sequence. This is however unlikely, since such inter-UAS DNA segments are very short (Fig. 1a) and the extension in the protection from DNase I (Pérez-Martín \& de Lorenzo, 1996a) cannot be explained. A more likely explanation is that ATP addition may initiate a nucleoprotein structure around which adjacent DNA sequences may wrap, so that the sharp DNA bends of the type IIB forms are in fact looped structures. This might be possible if ATP causes formation of an XylR $\Delta \mathrm{A}$ multimer with nonsaturated DNA-binding domains which can hold simultaneously two separated DNA sequences. Depending on the concentration of protein, such non-saturated domains may then either bind adjacent sequences in the same plasmid or engage sequences from two plasmids (Fig. 6). This could explain why the effect of adding ATP does not become truly significant until a certain concentration of XylR $\Delta$ A (e.g. $100 \mathrm{nM}$ in Fig. 4) has been added to the samples.

A simplified view of these events is presented in Fig. 6. It is assumed that, similar to NtrC (Rippe et al., 1998), the predominant form of XylR $\Delta \mathrm{A}$ in solution is a dimer. In the absence of ATP, such a dimer has a low affinity for the UAS, with which it interacts non-cooperatively. In the case of $\mathrm{NtrC}$, it has been shown that although protein dimers bind cooperatively to the UAS of the $g \ln A$ promoter in the absence of ATP (Porter et al., 1993), its phosphorylation increases such cooperativity (Porter et al., 1993). In the case of XylR $\Delta$ A, ATP addition causes a conformational change that increases the affinity and 
cooperativity of the protein-DNA interaction. In addition, it triggers the formation of an oligomer whose buildup requires recruitment of further XylR $\Delta \mathrm{A}$ proteins from solution and whose frame bears non-saturated DNA-binding domains. This is also compatible with the data available for NtrC. In this case, scanning force microscopy suggests that transcriptional activation of $g \ln A p 2$ may depend on the formation of an $\mathrm{NtrC}$ oligomer larger than a tetramer (Rippe et al., 1997; Wyman et al., 1997). Furthermore, analytical ultracentrifugation studies indicate that $\mathrm{NtrC}$ phosphorylation causes the formation of an octameric complex within the UAS of $g \ln A p 2$ (Rippe et al., 1998) with an ability to bind simultaneously two target DNA sequences. In fact, our TEM observations with XylR $\Delta \mathrm{A}$ are fully compatible with the hydrodynamic model proposed for NtrC (Rippe et al., 1998), suggesting that during activation two dimers are directly bound to the enhancer but are attached to two additional dimers through protein-protein interactions. The resulting octamer thus has the ability to bind DNA through two independent surfaces. Although we do not know what are the actual protein species resulting from adding ATP to $\mathrm{XylR} \Delta \mathrm{A}$, it is reasonable to believe that the the type IIB, IIC and III forms involve multimers, perhaps octamers, which can bind DNA through two separate surfaces.

A final piece of information from the TEM images presented in this work is the accumulation of just one type of DNA-protein complex in the presence of ATP $\gamma \mathrm{S}$ (Fig. 5), as compared to the diversity of forms with ATP (Fig. 4). At the lowest protein concentration assayed $(5 \mathrm{nM}), 99 \%$ of the plasmids were found forming single complexes with XylR $\Delta \mathrm{A}$, whereas more plasmids were engaged in the complexes at higher protein concentrations. The total lack of naked plasmids in these samples as compared to their presence in specimens treated with regular ATP, even at the highest protein concentrations $(100 \mathrm{nM})$, suggests that ATP hydrolysis causes the full dissassembly of the multimer and the return to the first step of what appears to be a cycle (Fig. $6)$.

\section{ACKNOWLEDGEMENTS}

The authors are indebted to S. Marco and J. Carrascosa for their assistance with TEM techniques. This research was supported by Contracts BIO4-CT97-2040 and QLRT-9900041 of the EU and by Grant BIO98-0808 of the Spanish Comisión Interministerial de Ciencia y Tecnología. J. G. was a predoctoral Fellow of the Hezkuntza Unibertsitate eta Ikerketa Saila - Eusko Jaurlaritza (Basque Government).

\section{REFERENCES}

Abril, M. A., Buck, M. \& Ramos, J. L. (1991). Activation of the Pseudomonas TOL plasmid upper pathway operon. J Biol Chem 266, 15832-15838.

Assinder, S. J. \& Williams, P. A. (1990). The TOL plasmids: determinants of the catabolism of toluene and xylenes. Adv Microb Physiol 31, 1-69.
Delgado, A. \& Ramos, J. L. (1994). Genetic evidence for activation of the positive transcriptional regulator XylR, a member of the $\mathrm{NtrC}$ family of regulators, by effector binding. J Biol Chem 269, 8059-8062.

Drummond, M., Whitty, P. \& Wooten, J. (1986). Sequence and domain relationships of $n t r C$ and nifA from Klebsiella pneumoniae: homologies to other regulatory proteins. EMBO J 5, 441-447.

Férnandez, S., de Lorenzo, V. \& Pérez-Martín, J. (1995). Activation of the transcriptional regulator XylR of Pseudomonas putida by release of repression between functional domains. Mol Microbiol 16, 205-213.

Inouye, S., Nakazawa, A. \& Nakazawa, T. (1988). Nucleotide sequence of the regulatory gene $x y l R$ of the TOL plasmid from Pseudomonas putida. Gene 66, 301-306.

Li, J., Passaglia, L., Rombel, I., Yan, D. \& Kustu, S. (1999). Mutations affecting motifs of unknown function in the central domain of nitrogen regulatory protein C. J Bacteriol 181, 5443-5454.

de Lorenzo, V., Herrero, M., Metzke, M. \& Timmis, K. N. (1991). An upstream XylR- and IHF-induced nucleoprotein complex regulates the $\sigma^{54}$-dependent $P u$ promoter of TOL plasmid. EMBO J 10, 1159-1167.

Maniatis, T., Fritsch, E. F. \& Sambrook, J. (1982). Molecular Cloning: a Laboratory Manual. Cold Spring Harbor, NY: Cold Spring Harbor Laboratory.

Morett, E. \& Segovia, L. (1993). The $\sigma^{54}$ bacterial enhancerbinding protein family: mechanism of action and phylogenetic relationship of their functional domains. J Bacteriol 175, 6067-6074.

North, A. K., Klose, K. E., Stedman, K. M. \& Kustu, S. (1993). Prokaryotic enhancer-binding proteins reflect eukaryote-like modularity: puzzle of nitrogen regulatory protein C. J Bacteriol 175, 4267-4273.

North, A. K., Weiss, D., Suzuky, H., Flashner, Y. \& Kustu, S. (1996). Repressor forms of the enhancer-binding protein NtrC: some fail in coupling ATP hydrolysis to open complex formation by $\sigma^{54}$ holoenzyme. J Mol Biol 260, 317-331.

Pérez-Martín, J. \& de Lorenzo, V. (1995). The amino-terminal domain of the prokaryotic enhancer-binding protein XylR is a specific intramolecular repressor. Proc Natl Acad Sci U S A 92, 9392-9396.

Pérez-Martín, J. \& de Lorenzo, V. (1996a). ATP binding to the $\sigma^{54}$ dependent activator XylR triggers a protein multimerization cycle catalyzed by UAS DNA. Cell 86, 331-339.

Pérez-Martín, J. \& de Lorenzo, V. (1996b). Physical and functional analysis of the prokaryotic enhancer of the $\sigma^{54}$-promoters of the TOL plasmid of Pseudomonas putida. J Mol Biol 258, 562-574.

Pérez-Martín, J. \& de Lorenzo, V. (1996c). In vitro activities of an $\mathrm{N}$-terminal truncated form of XylR, a $\sigma^{54}$-dependent transcriptional activator of Pseudomonas putida. J Mol Biol 258, 575-587.

Porter, S., North, A. K., Wedel, A. B. \& Kustu, S. (1993). Oligomerization of $\mathrm{NtrC}$ at the $\operatorname{gln} A$ enhancer is required for transcriptional activation. Genes Dev 7, 2258-2273.

Révet, B., Brahms, S. \& Brahms, G. (1995). Binding of the transcription activator NRI (NTRC) to a supercoiled DNA segment imitates association with the natural enhancer: an electron microscopic investigation. Proc Natl Acad Sci U S A 92, $7535-7539$.

Rippe, K., Guthold, M., Hippel, P. H. \& Bustamante, C. (1997). Transcriptional activation via DNA-looping: visualization of 
intermediates in the activation pathway of E. coli RNA polymerase $\sigma^{54}$ holoenzyme by scanning force microscopy. J Mol Biol 270, 125-138.

Rippe, K., Mücke, N. \& Schulz, A. (1998). Association states of the transcription activator protein $\mathrm{NtrC}$ from $E$. coli determinated by analytical ultracentrifugation. J Mol Biol 278, 915-933.
Wyman, C., Rombel, I., North, A. K., Bustamante, C. \& Kustu, S. (1997). Unusual oligomerization required for activity of NtrC, a bacterial enhancer-binding protein. Science 275, 1658-1661.

Received 11 February 2000; revised 17 April 2000; accepted 15 May 2000. 